\title{
Chromosome numbers of four species of Ochrosia sensu lato (Apocynaceae)
}

\author{
Hendrian $^{1}$, Tsuyoshi Motohashi ${ }^{1}$, Norikazu Tagashira ${ }^{2}$, \\ Goro Kokubugata $^{3}$, Mikio Aoyama ${ }^{4}$ and Katsuhiko Kondo ${ }^{1,3}$ \\ ${ }^{1}$ Laboratory of Plant Genetics and Breeding, Department of Agriculture, \\ Faculty of Agriculture, Tokyo University of Agriculture \\ 1737 Funako, Atsugi City, Kanagawa Prefecture 243-0034, Japan; \\ ${ }^{2}$ Hiroshima Jogakuin University, Hiroshima City, Japan; \\ ${ }^{3}$ Tsukuba Botanical Garden, National Science Museum, Tsukuba City 305-0005, Japan; \\ ${ }^{4}$ Botanical Garden, Graduate School of Science, Hiroshima University, Kagamiyama, \\ Higashi-Hiroshima City 739-8526, Japan \\ ${ }^{3}$ Author for correspondence (motohasi@nodai.ac.jp) \\ Received December 23, 2007; accepted March 24, 2007
}

\begin{abstract}
The chromosome numbers of four species of Ochrosia sensu lato (Apocynaceae) were reported: those of Neisosperma glomerata $(2 \mathrm{n}=22)$ and Neisosperma citrodora $(2 \mathrm{n}=23)$ were documented here for the first time, while those of Neisosperma oppositifolia $(2 \mathrm{n}=22)$ and Ochrosia coccinea $(2 \mathrm{n}=22)$ verified the previous counts.
\end{abstract}

KEYWORDS: Chromosome numbers, Ochrosia sensu lato

Cytological data in Ochrosia sensu lato has been very poorly known. Up to date, among approximately 40 species of Ochrosia sensu lato, only three have been documented their chromosome numbers, i.e. Ochrosia nakaiana $(2 \mathrm{n}=20)$, that was the first chromosome count for the genus (Ono 1975, 1977), O. coccinea $(2 \mathrm{n}=22)$ and O. oppositifolia $(2 \mathrm{n}=22)$ (Laan and Arends 1985).

Among the members of the Vinceae, the Apocynaceae intrageneric polyploidy occurs in Kopsia $(2 \mathrm{n}=36,72)$ and Rauvolfia $(2 \mathrm{n}=22,44,66,88)$; whilst interspecific polyploidy occurs in three species of Rauvolfia, i.e $R$. mannii $(2 \mathrm{n}=22,44), R$. serpentina $(2 \mathrm{n}=22,44)$, and $R$. vomitoria $(2 \mathrm{n}=22,66)$. In Catharanthus roseus intraspecific polyploidy is also found $(2 \mathrm{n}=16,24,32)$, but it is most likely due to horticultural selection (Laan and Arends 1985).

At the subfamily level in the Apocynaceae, the most comprehensive information on the chromosome numbers perhaps was the Albers and Meve's article (2001), who published a list of chromosome numbers of 672 species (out of 740 of the three subfamilies: Asclepiadoideae, Periplocoideae, and Secamonoideae), 299 of which were the first counts for the taxa. The basic chromosome number of $x=11$ was found to be predominant, occurring in ca. $96 \%$ of the taxa investigated. Deviations from the basic chromosome number of $\mathrm{x}=11$ were absent in Periplocoideae and Secamonoideae, but some variation was present in Asclepiadoideae. A reduction to $\mathrm{x}=10$ was known only in advanced tribe Asclepieae; whilst an increase $(x=12,13,14)$ was found rarely and sporadically in the subfamily Asclepiadoideae (Albers and Meve 2001).

Although the Apocynaceae are woody in general it also comprises some herbaceous genera, which are considered as derived within the family. The basic chromosome numbers of some of the herbaceous genera in the family are listed as follows: Catharanthus $(\mathrm{x}=8)$, Apocynum $(\mathrm{x}=8,11)$, Trachomitum $(\mathrm{x}=8,11)$, Trachelospermum ( $\mathrm{x}=10)$, Amsonia $(\mathrm{x}=11)$, Rhyaza $(\mathrm{x}=11)$, and Vinca $(\mathrm{x}=23)$. As the basic chromosome number of $\mathrm{x}=11$ is the primitive number in the family, on the basis of the evidence from those above mentioned genera, in Apocynaceae it seems that there is no correlation between a derived life form and a derived chromosome number (Laan and Arends 1985).

\section{Materials and Methods}

Four species of Ochrosia used were collected in their localities and cultivated in Bogor Botanical Garden and Purwodadi Botanical Garden, Indonesia (see Table 1). Seeds of those species were grown in the greenhouse of the Laboratory of Plant Chromosome and Gene Stock, Graduate School of Science, Hiroshima University. They were planted in pots and their shoot apices and root tips were harvested for chromosome studies.

Pretreatment was done by immersing the root tips in $0.002 \mathrm{M}$ 8-hydroxyquinoline solution for $3.5 \mathrm{~h}$ at room temperature. Then, they were fixed in the 3:1 of ethanol and acetic acid solution at $4^{\circ} \mathrm{C}$ overnight. They were rinsed in distilled water and $45 \%$ acetic acid for $10 \mathrm{~min}$ each at room temperature before macerated in the $3: 1$ of $1 \mathrm{~N} \mathrm{HCl}$ and $45 \%$ acetic acid solution, at $60^{\circ} \mathrm{C}$ for $5 \mathrm{~min}$. They, then, were washed in distilled water for $5 \mathrm{~min}$, stained with $2 \%$ aceto-orcein, and squashed in one drop of $45 \%$ acetic acid on glass slide. 
Table 1. Species, sources, and the chromosome numbers of Ochrosia

\begin{tabular}{|c|l|l|l|c|}
\hline No. & \multicolumn{1}{|c|}{ Species } & \multicolumn{1}{|c|}{ Cultivation site } & \multicolumn{1}{c|}{ Source } & $\begin{array}{c}\text { Chromosome } \\
\text { number }(2 \mathrm{n})\end{array}$ \\
\hline \multirow{2}{*}{1.} & Neisosperma glomerata & $\begin{array}{l}\text { vak VIII.G.191 } \\
\text { Bogor Botanical Garden, Indonesia }\end{array}$ & Moluccas, Indonesia & 22 \\
\cline { 3 - 5 } & $\begin{array}{l}\text { vak XX.E.16 } \\
\text { Purwodadi Botanical Garden, Indonesia }\end{array}$ & Papua, Indonesia & 22 \\
\hline \multirow{2}{*}{2.} & \multirow{2}{*}{ N. oppositifolia } & $\begin{array}{l}\text { vak IV.A.176 } \\
\text { Bogor Botanical Garden, Indonesia }\end{array}$ & Sumatra, Indonesia & 22 \\
\cline { 3 - 6 } & $\begin{array}{l}\text { vak XX.C.3 } \\
\text { Purwodadi Botanical Garden, Indonesia }\end{array}$ & Timor Island, Indonesia & 22 \\
\hline \multirow{2}{*}{3.} & N. citrodora & $\begin{array}{l}\text { vak IV.A.200 } \\
\text { Bogor Botanical Garden, Indonesia }\end{array}$ & Papua, Indonesia & 22 \\
\hline
\end{tabular}

\section{Results and Discussion}

Chromosome numbers Neisosperma glomerata (Fig. 1A.) is distributed widely in the Malesian region. It is mostly found in primary and secondary forests, beach forests, or swampy areas, on red lateritic clay, stony soil, or black soil, at the altitude of 2 $900 \mathrm{~m}$ asl. In the present study, the chromosome number was counted based on two accessions from Moluccas and Papua (Indonesia). The chromosome number was $2 \mathrm{n}=22$, that was recorded here for the first time.

Neisosperma citrodora (Fig. 1B) is found in Papua, Indonesia. The species mostly occurs in lowland forests or swampy areas, on stony or copper-rich soil. In the present study, the chromosome number was counted based on one accession only. This species showed the chromosome number of $2 n=23$ here for the first time.

Since the basic chromosome number of $\mathrm{x}=11 \mathrm{might}$ be regarded as the primary number of the Apocynaceae by some authors (Laan and Arends 1985, Albers et al. 1993, Albers and Meve 2001), there would most probably included a B-chromosome according to its karyotype. The occurrence of B-chromosome is known to be restricted to individual plant, and the chromosome number of $2 n=23$ would not be represented in the species as a whole. The presence of two B-chromosomes in Pentarrhinum insipidum in the Asclepiadoideae, the Apocynaceae was reported by Liede et al. (2002). However, the occurrence of B-chromosome in the
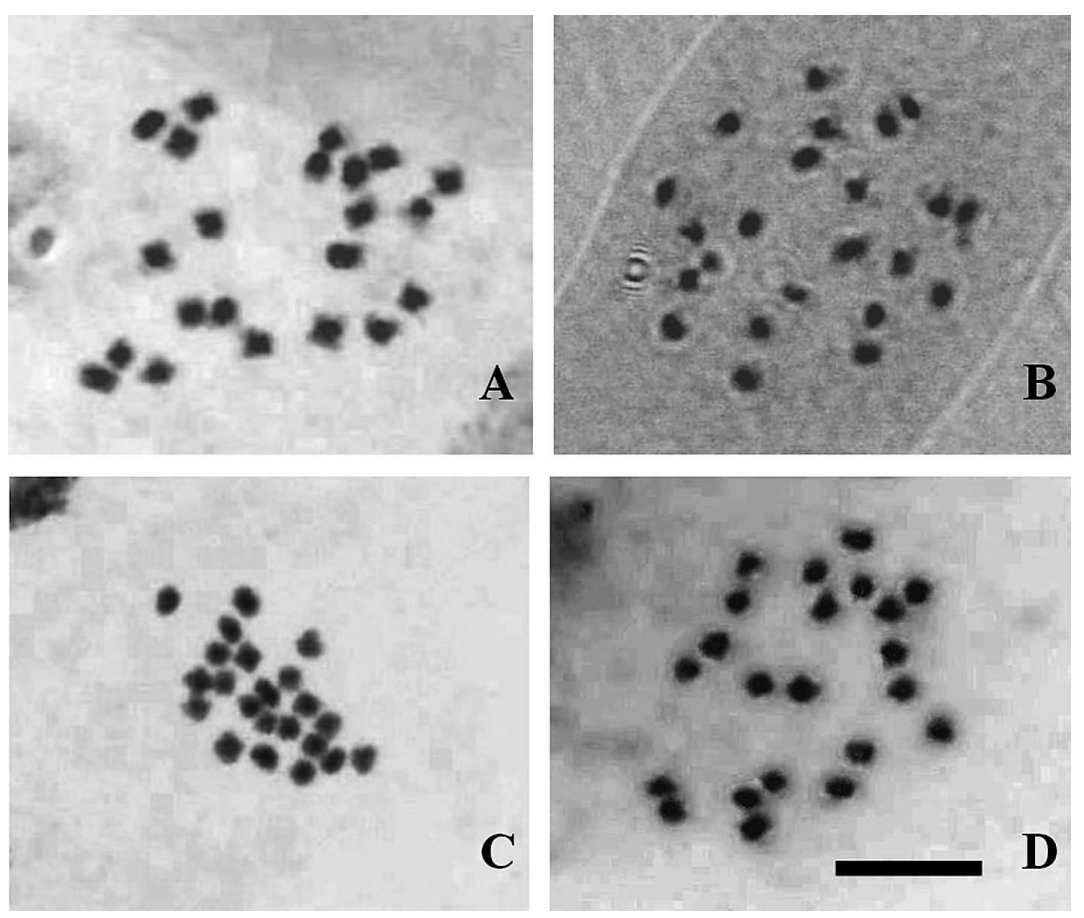

Fig 1. Somatic metaphase chromosomes of four species of Ochrosia sensu lato studied. Neisosperma glomerata $(2 \mathrm{n}=22)$, B. Neisosperma citrodora $(2 \mathrm{n}=23)$, C. Neisosperma oppositifolia $(2 \mathrm{n}=22)$, D. Ochrosia coccinea $(2 \mathrm{n}$ $=22$ ). $\mathrm{Bar}=10 \mu \mathrm{m}$ 
Apocynaceae has been very rarely reported.

Neisoisperma oppositifolia (Fig.1C) among the members of Ochrosia sensu lato is most widely distributed from Sri Lanka, Northern Thailand, Malaysia down to Pacific Islands and has a wide-range of habitats at the altitude of $0 \sim 200 \mathrm{~m}$ asl. In the present study, the chromosome number of the species was counted based on one each accession from Sumatra and Timor Island, Indonesia. The chromosome number for the species was $2 n=22$. This chromosome number verified the previous count by Laan and Arends (1985). They used the plants cultivated in Wageningen University, the Netherlands. However, they did not mention any information about the provenance.

Ochrosia coccinea (Fig. 1D) occurs in Moluccas and Papua, Indonesia as well as East Sepik, Papua New Guinea. It is mostly found on clay soil, at the altitude of $0 \sim 1000 \mathrm{~m}$ asl. Two accessions of the species both collected in different localities in Moluccas, Indonesia showed the chromosome number of $2 n=22$ that verified the previous count by Laan and Arends (1985).

General characters of the chromosomes in Ochrosia sensu lato: Small and homogeneous The chromosomes of the four species examined were commonly small. Laan and Arends (1985) reported that the chromosomes of the woody Apocynaceae were commonly small. The sizes of the somatic metaphase chromosomes in tribe Vinceae falls within the range of 0.5-1.5 $\mu \mathrm{m}$. The smallest length of $0.5 \mu \mathrm{m}$ was found in Rauvolfia caffra and R. mannii.

The four species investigated showed commonly more or less homogeneous, having approximately same size and shape. However, exact position of the centromeres could not be detected due to small size of the chromosomes.

Laan and Arends (1985) reported that the karyotypes in the Apocynaceae were generally symmetrical and the chromosomes within a karyotype were similar length with primary constrictions usually in median position. According to Stebbins (1974), such chromosomes were possessed by the great majority of vascular plants. Evolutionary trends occur towards greater asymmetry, including both increasing difference in size between the chromosome of the same karyotype and shifts of the centromere from median to subterminal or even to terminal position.

Chromosome numbers and morphology In the present study, species with different morphological characters such as Neisosperma glomerata (Fig. 2A) and $N$. oppositifolia (Fig. 2C) both with fine fibrous endocarp and Ochrosia coccinea (Fig. 2D) with massive endocarp were found to have same chromosome number.

On the other hand, Neisosperma nakaiana and $N$. glomerata showed quite similar chromosomes in morphology but were found to have different chromosome numbers.

Chromosome numbers and molecular phylogeny Although Neisosperma nakaiana and N. glomerata were the closest relatives phylogenetically (Hendrian and Kondo 2007a, b, c; Hendrian et al. submitted), their chromosome numbers were different from each other: the
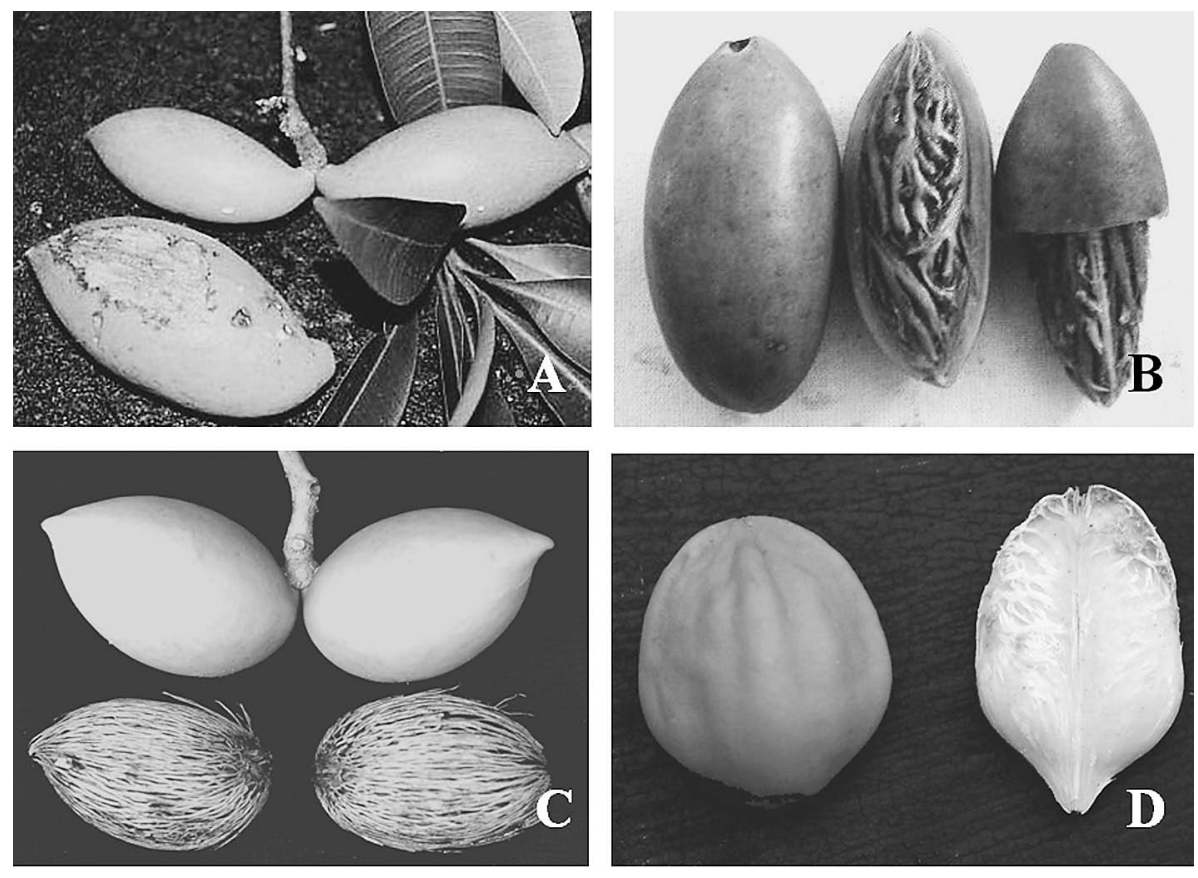

Fig. 2. Fruits of four species of Ochrosia sensu lato. A. Neisosperma glomerata, B. Neisosperma citrodora, C. Neisosperma oppositifolia, D. Ochrosia coccinea. 
chromosome number of $N$. nakaiana was $2 \mathrm{n}=20$ and that of $N$. glomerata was $2 \mathrm{n}=22$. The chromosome number of $N$. glomerata was similar to $N$. oppositifolia, and even to Ochrosia coccinea which was not phylogenetically closely related and placed further in a separate clade.

\section{Chromosome numbers and biogeography Neisosperma} glomerata, N. citrodora, N. oppositifolia, and Ochrosia coccinea studied here with the basic chromosome number of $\mathrm{x}=11$ were all occurred in Malesian Region. Neisosperma oppositifolia occurs in Malesia and also in some other areas outside the region. Neisosperma nakaiana, only the species which had the basic chromosome number of $\mathrm{x}=10$ was endemic to Ogasawara Islands, Japan. According to Takhtajan's floristic provinces (Takhtajan 1986), the Islands are placed in the Eastern Asiatic (SinoJapanese) Region. Thus, the species would be biogeographically different from those of Malesian ones.

Ogasawara Islands are considerably specific with respect to its geology. The crust of the Ogasawara Islands was formed by volcanic activity and is composed mostly of an andesitic volcanic rock, which is rich in magnesium oxide, chromium, and silicon dioxide. The uniqueness of these areas is also shown by the high degree of endemism. Thus, the change in chromosome number by reduction from $\mathrm{x}=11$ to $\mathrm{x}=10$ ) probably has relation with adaptation to this specific environment.

To summarize, based on the evidences available at present in Ochrosia sensu lato there is no indication of a possible correlation between chromosome number and morphological appearances, and between chromosome number and molecular-based phylogeny. However, it should also be considered that in some other cases chromosomal information has been proved to be an important element in taxonomy and phylogenetic studies in some taxa of different rank, such as in the Annonaceae (Walker 1972), the angiosperm (Raven 1975), Biebersteinia, the Geraniaceae (Liu et al. 2001), and Lupinus (Conterato and Schifino-Wittmann 2006) and Crotalaria (Flores et al. 2006) both of the Fabaceae.

As shown by Neisosperma nakaiana, the variation of chromosome number in Ochrosia sensu lato is probably related to biogeography of the species and in particular, to adaptation to specific environment.

However, this is only a preliminary study based on very limited evidences available at present. Further studies involving more Ochrosia sensu lato species is certainly needed to achieve a better understanding concerning variation of chromosome number within the genus, their pattern, and also possible correlation between the chromosome numbers and other aspects such as morphological characters, molecular phylogeny, biogeography, and so on.
ACKNOWLEDGEMENT. The authors have been fully supported by Dissertation PhD Program for 2006 (LIPI 10617), the Japan Society for the Promotion of Science. This study was financially supported by the Grant-in-Aid for Scientific Research Program (A) No. 19255004 of Japan Society for the Promotion of Science (Representative: Katsuhiko Kondo).

\section{LiTERATURE CiTED}

Albers, F., Liede, S. and Meve, U. 1993. Deviating chromosome numbers in Asclepiadaceae. Nordic Journ. Botany 13: 37-39.

Albers, F. and Meve, U. 2001. A karyological survey of Asclepiadoideae, Periplocoideae, and Secamonoideae, and evolutionary considerations within Apocynaceae s.l. Ann. Missouri Bot. Gard. 88: 624-656.

Conterato, I. F. and Schifino-Wittmann, M. T. 2006. New chromosome numbers, meiotic behaviour and pollen fertility in American taxa Lupinus (Leguminosae): contributions to taxonomic and evolutionary studies. Bot. Journ. Linnean Soc. London 150: 229-240.

Flores, A. S., Correa, A. M., Forni-Martins, E. R. and Tozzi, A. M. G. A. 2006. Chromosome numbers in Brazilian species of Crotalaria (Leguminosae, Papilionoideae) and their taxonomic significance. Bot. Journ. Linnean Soc. London 151: 271-277.

Hendrian and Kondo, K. 2007a. Molecular phylogeny of Ochrosia sensu lato (Apocynaceae) based on ITS sequences data: an evidence for the inclusion of Neisosperma. Chrom. Bot. 2: 127-132.

Hendrian and Kondo, K. 2007b. Molecular phylogeny of Ochrosia sensu lato (Apocynaceae) based on rps 16 intron and ITS sequences data: supporting the inclusion of Neisosperma. Chrom. Bot. 2: 133-140.

Hendrian and Kondo, K. 2007c. The monophyly of Ochrosia sensu lato (Apocynaceae): evidence from ITS, rps 16 intron and morphological characters. Chrom. Bot. 2: 141-149.

Hendrian, Masuda, Y. and Kondo, K. Phylogeny of Ochrosia sensu lato (Apocynaceae) based on combined molecular and morphological data: inferred by Bayesian approach. (submitted).

Laan, F. M. van der and Arends, J. C. 1985. Cytotaxonomy of Apocynaceae. Genetica 68: 3-35.

Liede, S., Meve, U. and Tauber, A. 2002. What is the subtribe Glossonematinae (Apocynaceae: Asclepiadoideae)? A phylogenetic study based on cpDNA spacer. Bot. Journ. Linnean Soc. London 139: 145-158.

Liu, J., Ho, T., Chen, S. and Lu, A. 2001. Karyomorphology of Biebersteinia Stephan (Geraniaceae) and its systematic and taxonomic significance. Bot. Bull. Acad. Sinica 42: 61-66.

Ono, M. 1975. Chromosome numbers of some endemic species of the Bonin Islands I. Bot. Mag. Tokyo 88: 323328.

Ono, M. 1977. Cytotaxonomical studies on the flowering plants endemic to the Bonin Islands. Mem. Nat. Sci. Mus. 10: 63-80.

Raven, P. 1975. The bases of angiosperm phylogeny: cytology. Ann. Missouri Bot. Gard. 62: 724-764.

Stebbins, G. L. 1974. Flowering plants evolution above the species level. The Belknap Press of Harvard Univ. Press, Cambridge, Massachusetts.

Takhtajan, A. 1986. Floristic region of the world. Univ. Calif. Press, Berkeley.

Walker, J. W. 1972. Chromosome numbers, phylogeny, phytogeography of the Annonaceae and their bearing on the (original) basic chromosome number of angiosperms. Taxon 21: 57-65. 